\title{
Role of malate dehydrogenase in facilitating lactate dehydrogenase to support the glycolysis pathway in tumors
}

\author{
SIAVASH MANSOURI $^{1,2}$, ALI SHAHRIARI ${ }^{1}$, HADI KALANTAR ${ }^{3}$, \\ TARANEH MOINI ZANJANI ${ }^{4}$ and MOJTABA HAGHI KARAMALLAH ${ }^{5}$
}

${ }^{1}$ Department of Biochemistry and Molecular Biology, Faculty of Veterinary Medicine, Shahid Chamran University of Ahvaz, Ahvaz, Khuzestan 61357-83151, Iran; ${ }^{2}$ Department of Internal Medicine II, Saarland University Medical Center, D-66421 Homburg, Germany; ${ }^{3}$ Department of Pharmacology, School of Pharmacy, Ahvaz Jundishapur University of Medical Sciences, Ahvaz, Khuzestan 61357-33184; ${ }^{4}$ Department of Pharmacology, School of Medicine, Shahid Beheshti University of Medical Sciences, Tehran 19857-17443; ${ }^{5}$ Department of Biochemistry and Molecular Biology, International Campus, Shahid Sadoughi University of Medical Sciences, Yazd 89151-73143, Iran

Received September 21, 2016; Accepted December 14, 2016

DOI: $10.3892 /$ br.2017.873

\begin{abstract}
High aerobic glycolysis, as one of the hallmarks of cancer cells, requires nicotinamide adenine dinucleotide $\left(\mathrm{NAD}^{+}\right)$as a vital co-factor, to guarantee the flow of glycolysis. Malate dehydrogenase $(\mathrm{MDH})$, as an important enzyme in cancer metabolism, is a source of $\mathrm{NAD}^{+}$additional to lactate dehydrogenase (LDH). The current study aimed to elucidate the kinetic parameters of MDH in human breast cancer and evaluate its supportive role in the glycolysis pathway. The Michaelis-Menten constant $\left(\mathrm{K}_{\mathrm{m}}\right)$ and maximum velocity $\left(\mathrm{V}_{\max }\right)$ of $\mathrm{MDH}$ were determined in the crude extracts of human breast tumors and healthy tissue samples, which were obtained directly from the operating theatre. To assess the potential role of $\mathrm{MDH}$ in supporting glycolysis, the $\mathrm{MDH}$ activity was measured when the LDH activity was inhibited by different concentrations of oxamate, an inhibitor of LDH in breast cancer cell lines. The $\mathrm{K}_{\mathrm{m}}$ of cancerous $\mathrm{MDH}$ (C-MDH) was the same as the healthy $\mathrm{MDH}$, although the $\mathrm{V}_{\max }$ of $\mathrm{C}-\mathrm{MDH}$ was higher relative to the healthy MDH. Notably, the MDH activity was increased in the MDA-MB-231 cell line, which was treated with the LDH inhibitor (oxamate), but not in the MCF-7 cell line $(\mathrm{P}<0.05)$. The higher tendency of $\mathrm{C}-\mathrm{MDH}$ for $\mathrm{NAD}^{+}$and malate generation in cancer cells is an effective approach for supporting glycolysis. Increasing MDH activity in the absence of LDH demonstrates the supportive role of
\end{abstract}

Correspondence to: Dr Ali Shahriari, Department of Biochemistry and Molecular Biology, Faculty of Veterinary Medicine, Shahid Chamran University of Ahvaz, Golestan Street, Ahvaz, Khuzestan 61357-83151, Iran

E-mail: a.shahriari@scu.ac.ir

Key words: malate dehydrogenase, lactate dehydrogenase, glycolysis, breast cancer
MDH in glycolysis. Therefore, decreasing MDH activity and expression in a forward reaction may present as a valid molecular target to abolish its potential effect on tumor metabolism.

\section{Introduction}

High aerobic glycolysis is a predominant feature of cancer cells, which is termed the Warburg effect $(1,2)$. This bioenergetic and metabolic characteristic permits cancer cells to survive under adverse tumor conditions (such as hypoxia) and enables them to proliferate and invade, subsequently leading to distant metastasis (3). The control point of glycolysis is glyceraldehyde 3-phosphate dehydrogenase that requires nicotinamide adenine dinucleotide $\left(\mathrm{NAD}^{+}\right)$in the glycolytic direction. Cancer cells provide the required $\mathrm{NAD}^{+}$via lactate dehydrogenase (LDH), which converts pyruvate to lactate with concomitant regeneration of $\mathrm{NAD}^{+}$. The gene expression and activity of $\mathrm{LDH}$ is increased in various types of tumor when compared with healthy tissue samples (4-6). However, there is another approach that supplies the required $\mathrm{NAD}^{+}$for glycolysis, which is cytosolic malate dehydrogenase $(\mathrm{MDH})(7,8)$. $\mathrm{MDH}$, as a part of the malate-aspartate shuttle, catalyzes the reversible reaction of oxaloacetate (OAA) to malate in the presence of NADH. Typically, the enzyme has two distinct forms, mitochondrial and cytosolic. The cytosolic isoform is involved in the oxidation of NADH to $\mathrm{NAD}^{+}$, which is then used for continuing the progression of glycolysis (9).

Environmental parameters, such as $\mathrm{pH}$, oxygen and nutrient availability, influence the enzyme kinetics via different approaches (10). The tumor microenvironment is defined as a heterogeneous milieu in which the oxygen pressure, $\mathrm{pH}$ and nutrient availability are completely different from healthy tissues (11). However, the nature and importance of the tumor environment on enzyme kinetics has been masked in certain enzyme studies, owing to the use of cell culture conditions in which $\mathrm{pH}$ is in the normal range, without any fluctuation, and where oxygen and nutrients are constantly accessible (12). Alteration of the enzyme characteristics 
in the tumor microenvironment, which alters the enzyme kinetics, has received little attention. Given the potential role of $\mathrm{MDH}$ to supply $\mathrm{NAD}^{+}$and the effect of stressful tumor microenvironment on enzyme kinetics, the aim of the current study was to compare the kinetic parameters of $\mathrm{MDH}$ between breast cancer tissue samples and cell lines (MCF-7 and MDA-MB-231) and healthy mammary tissue samples. Furthermore, the potential role of $\mathrm{MDH}$ for sustaining the glycolysis pathway in breast cancer cells was investigated.

\section{Materials and methods}

Clinical sample collection. Ten human breast tumor samples were obtained from Apadana Hospital (Ahvaz, Iran) during the mastectomy procedure from February 2012 to September 2013. Healthy tissue samples away from the tumor were included as controls. Two independent expert pathologists from the pathology laboratory of Apadana Hospital performed the pathological tumor tissue examination. Samples were immediately preserved in liquid nitrogen, transported to the laboratory and stored at $-80^{\circ} \mathrm{C}$. The study was approved by the ethics committee from Jundishapour Medical University of Ahvaz (Ahvaz, Iran; associated with Apadana Hospital) and conducted according to the Guide for Human study by the National Academy of Sciences (National Institutes of Health), and informed consent was obtained from all patients involved in the study.

Sample preparation. Frozen tumor and healthy tissue samples were homogenized $(1: 5 ; \mathrm{w}: \mathrm{v})$ in ice cold homogenization buffer (20 mM Tris-HCl, pH 8.0, 10 mM 2-mercaptoethanol, $10 \%$ v:v glycerol, 2 mM EDTA, 2 mM EGTA and $20 \mathrm{mM}$ $\beta$-glycerophosphate) and a few crystals of phenylmethylsulphonyl fluoride were added at the time of homogenization. Samples were homogenized using a Miccra homogenizer (MICCRA GmbH, Müllheim, Germany), centrifuged for $10 \mathrm{~min}$ at $10,000 \mathrm{x} \mathrm{g}$ at $4^{\circ} \mathrm{C}$ to remove tissue debris. The supernatant was then centrifuged for $30 \mathrm{~min}$ at $25,000 \mathrm{x}$ g at $4^{\circ} \mathrm{C}$ to obtain high speed supernatant that contained the cytoplasmic enzymes (13). Finally, the supernatant was decanted and held on ice until use. Low molecular weight metabolites and ions were removed from the supernatant by Sigma-Aldrich Sephadex G-25 columns (1x5 cm; Merck KGaA, Darmstadt, Germany) equilibrated in the homogenizing buffer. The samples were then pooled and held at $4^{\circ} \mathrm{C}$ until use for subsequent enzyme kinetic characterization.

Cell culture, cell suspension, cell homogenate and cytosolic fraction preparation. MCF-7 and MDA-MB-231 cells were obtained from the Pasteur Institute Collection of Cell Cultures (Tehran, Iran). MCF-7 and MDA-MB-231 cells were maintained at $37^{\circ} \mathrm{C}$ in the presence of $5 \% \mathrm{CO} 2$ in RPMI-1640 supplemented with $10 \%$ inactivated fetal bovine serum, $2 \mathrm{mM}$ glutamine, $100 \mathrm{U} / \mathrm{ml}$ penicillin and $100 \mu \mathrm{g} / \mathrm{ml}$ streptomycin. Prior to each experiment, the culture medium was removed and the plated MCF-7 and MDA-MB-231 cells were washed with phosphate-buffered saline (PBS) medium containing $138 \mathrm{mM} \mathrm{NaCl}, 2.7 \mathrm{mM} \mathrm{KCl}, 8 \mathrm{mM} \mathrm{Na}_{2} \mathrm{HPO}_{4}, 15 \mathrm{mM} \mathrm{KH}_{2} \mathrm{PO}_{4}$, $\mathrm{pH} 7.4$, and collected by trypsinization into $1 \mathrm{ml} \mathrm{PBS}$ medium. Cells $\left(\sim 30 \times 10^{5}\right.$, grown to $80 \%$ confluence) were suspended in
$3 \mathrm{ml}$ cold isolation buffer $(0.32 \mathrm{M}$ sucrose, $1 \mathrm{mM}$ EDTA and $10 \mathrm{mM}$ Tris-HCl, pH 7.5). Cytosolic fractions were obtained according to a previous study (14) with certain modifications. Briefly, cells were homogenized at $4^{\circ} \mathrm{C}$ with a Miccra homogenizer and centrifuged at $25,000 \times \mathrm{g}$ for $30 \mathrm{~min}$ at $4^{\circ} \mathrm{C}$ to obtain supernatant, which contained the cytoplasmic enzymes.

Effect of oxamate on $\mathrm{LDH}$ and $\mathrm{MDH}$ activity. To evaluate the effect of oxamate (Appliechem $\mathrm{GmbH}$, Darmstadt, Germany) on cell proliferation and select the appropriate oxamate concentration, cells were plated into 96-well, flat-bottomed plates at $2-4 \times 10^{3}$ cells $/ 100 \mu \mathrm{l}$ per well. After the overnight incubation at $37^{\circ} \mathrm{C}$, triplicate wells were treated with varying concentrations of oxamate, ranging from 5 to $80 \mathrm{mM}$ for 3 days. The relative percentage of metabolically active cells relative to the untreated controls was then determined on the basis of the mitochondrial conversion of 3-(4,5-dimethylthiazol-2-yl)-2,5-diphenyltetrazolium bromide to formazine. The quantity of 3-(4,5-dimethylthiazol- 2-yl)-2,5-diphenyltetrazolium bromide that is converted to formazine indicates the number of viable cells. The results were assessed in a 96-well format plate reader by measuring the absorbance at a wavelength of $540 \mathrm{nM}$ (A540 nm). The percentage of metabolically active cells was compared with the percentage of control cells growing in the absence of oxamate in the same culture plate. The half maximal inhibitory concentrations $\left(\mathrm{IC}_{50}\right)$ were determined by nonlinear regression analysis using the equation for a sigmoid plot. The MCF-7 and MDA-MB-231 cells were seeded in 25- $\mathrm{cm}^{2}$ flasks in duplicate. MCF-7 cells were treated (based on the $\mathrm{IC}_{50}$ results) with 30 and $60 \mathrm{mM}$ oxamate, and MDA-MB-231 cells were treated with 10 and $20 \mathrm{mM}$ oxamate for $72 \mathrm{~h}$, with untreated cells serving as controls. Oxamate was administered at a cell confluency of $70 \%$ for each cell line. After $72 \mathrm{~h}$, cells were harvested and processed for cell lysate preparation according to the previous method for cell culture preparation. LDH activity was determined by monitoring the rate of conversion from NADH to $\mathrm{NAD}^{+}$in the present of $1.5 \mathrm{mM}$ pyruvate and $0.25 \mathrm{mM}$ NADH. MDH activity was measured using the same method as for LDH, with $1 \mathrm{mM}$ OAA used instead of pyruvate as a substrate. The results were normalized to the LDH and MDH activity per protein content. The protein concentrations were quantified using the Bradford protein assay (15), and experiments were performed in triplicate.

Enzyme assay and kinetic parameters. MDH activity was measured in the presence of OAA with NADH as substrates for the forward reaction and malate with $\mathrm{NAD}^{+}$as substrates for the reverse reaction. The lowest concentration of each substrate, which demonstrated maximum velocity, constant rate of product formation and linear regressions of activities for serial dilutions of enzyme, was assigned as the optimum substrate concentration.

Reactions were initiated by adding $10 \mu \mathrm{l}$ of crude enzyme to a $200-\mu$ l total reaction volume by using $20 \mathrm{mM}$ Tris-Hcl buffer $(\mathrm{pH} 8)$ in the microplate well. Activity was monitored at $340 \mathrm{nM}(A 340 \mathrm{~nm})$ for assessing the conversion of NADH to $\mathrm{NAD}^{+}$(or vice versa) by using a BioTek PowerWave X2 microplate reader (BioTek Instruments, Inc., Winooski, VT, USA) and Gen5 version 2.0 software (BioTek Instruments, Inc.; kinetic mode, reading interval=39 sec). 
Data were analyzed using microplate analysis and kinetics programs $3.51(16,17)$. Kinetics 3.51 computer program fitted data through a nonlinear least squares regression for determination of the Michaelis-Menten constant $\left(\mathrm{K}_{\mathrm{m}}\right.$; the substrate concentration resulting in half-maximal activity) and maximum velocity $\left(\mathrm{V}_{\max }\right)$ values.

The $\mathrm{K}_{\mathrm{m}}$ and $\mathrm{V}_{\max }$ were calculated from the mean of three separate series of determinations. Total protein content was measured using the Bradford method and bovine serum albumin (Sigma-Aldrich; Merck KGaA) as standard. Due to the potential existence of endogenous NADH to NAD ${ }^{+}$ interconversion (i.e., NADH oxidation by complex I activity) in the crude extract, the NADH to $\mathrm{NAD}^{+}$interconversion was surveyed in each sample to eliminate the possible existence of its effect. This interconversion was determined by adding the NADH (0.5-1 mM) or NAD ${ }^{+}(3-5 \mathrm{mM})$ into the samples and monitoring the absorbance change at $340 \mathrm{~nm}$.

Statistical analysis. Data were expressed as the mean \pm SEM, from independent determinations on separate preparations of enzymes. Data were analyzed using Student's t-test and $\mathrm{P}<0.05$ was considered to indicate a statistically significant difference.

\section{Results}

Kinetic properties of $M D H$ and $L D H$. Optimum assay conditions for $\mathrm{MDH}$ in the forward reaction were $1 \mathrm{mM}$ OAA and $0.25 \mathrm{mM}$ NADH in tumor and healthy tissue samples, and $1.5 \mathrm{mM}$ pyruvate and $0.25 \mathrm{mM}$ for $\mathrm{LDH}$. It should be noted that no NADH to NAD+ interconversion activity (or vice versa) was observed in the crude extract samples.

The maximal activity of $\mathrm{MDH}$ in tumor samples for malate formation $(6,978 \pm 9.1 \mathrm{mU} / \mathrm{g})$ was significantly greater than the values in the healthy tissue samples $(5,651 \pm 12.7 \mathrm{mU} / \mathrm{g}$; Table I) $(\mathrm{P}<0.05)$. The $\mathrm{K}_{\mathrm{m}}$ OAA of MDH were not identified to be significantly different between the tumor $(0.023 \pm 0.004 \mathrm{mM})$ and healthy $(0.02 \pm 0.006 \mathrm{mM})$ samples $(\mathrm{P}>0.05)$. The maximal activity of $\mathrm{LDH}$ in the tumor samples for lactate formation $(8,476 \pm 7.2 \mathrm{mU} / \mathrm{g})$ was significantly higher than that of the healthy tissue samples $(5,330 \pm 9.2 \mathrm{mU} / \mathrm{g})(\mathrm{P}<0.05$; Table I).

Effect of oxamate on $\mathrm{LDH}$ and $\mathrm{MDH}$ activity. The effect of oxamate on $\mathrm{LDH}$ and $\mathrm{MDH}$ activity in the MCF-7 cell lines was evaluated at two concentrations, 30 and $60 \mathrm{mM}$. Compared with the control $(9.087 \pm 0.07 \mathrm{mU} / \mathrm{mg}), \mathrm{LDH}$ activity was not significantly decreased by $30 \mathrm{mM}$ oxamate after $72 \mathrm{~h}$ $(8.8 \pm 0.20 \mathrm{mU} / \mathrm{mg})$; however, $60 \mathrm{mM}$ oxamate significantly decreased LDH activity $(6.73 \pm 0.09 \mathrm{mU} / \mathrm{mg})$. Following treatment with $60 \mathrm{mM}$ oxamate $(\mathrm{P}<0.05), \mathrm{MDH}$ activity remained stable and was not significantly changed in the MCF-7 cell line (Fig. 1; P>0.05).

LDH and MDH activity of MDA-MB-231 were measured following treatment with 10 and $20 \mathrm{mM}$ oxamate for $72 \mathrm{~h}$. Compared with the control $(10.763 \pm 0.17 \mathrm{mU} / \mathrm{mg}), \mathrm{LDH}$ activity of MDA-MB-231 was significantly decreased by treatment with $10 \mathrm{mM}(9.53 \pm 0.06 \mathrm{mU} / \mathrm{mg})$ and $20 \mathrm{mM}(7.87 \pm 0.1 \mathrm{mU} / \mathrm{mg})$ oxamate $(\mathrm{P}<0.05)$. Notably, MDH activity was increased by $\sim 3$-fold following treatment with $10(2.183 \pm 0.20 \mathrm{mU} / \mathrm{mg})$ and $20 \mathrm{mM}(2.153 \pm 0.29 \mathrm{mU} / \mathrm{mg})$ oxamate compared with the control (0.785 $\pm 0.06 \mathrm{mU} / \mathrm{mg}$; Fig. 2$)$, and no significant
Table I. Kinetic parameters of malate dehydrogenase and lactate dehydrogenase from breast tumor and healthy tissue samples.

\begin{tabular}{llc}
\hline Kinetic parameter & \multicolumn{1}{c}{ Tumor } & Healthy \\
\hline $\mathrm{K}_{\mathrm{m}}$ OAA $(\mathrm{mM})$ & $0.023 \pm 0.004$ & $0.02 \pm 0.006$ \\
$\mathrm{~V}_{\max }$ OAA $(\mathrm{mU} / \mathrm{g})$ & $6,978 \pm 9.1^{\mathrm{a}}$ & $5,651 \pm 12.7$ \\
$\mathrm{~V}_{\max }$ pyruvate $(\mathrm{mU} / \mathrm{g})$ & $8,476 \pm 7.2^{\mathrm{a}}$ & $5,330 \pm 9.2$ \\
\hline
\end{tabular}

Assays were conducted at $25^{\circ} \mathrm{C}$ and data are presented as the mean \pm standard error of the mean, $(n=3)$. Independent determinations were performed on each of the 10 tumor and normal samples. ${ }^{a} \mathrm{P}<0.05$ vs. healthy. $\mathrm{K}_{\mathrm{m}}$, Michaelis-Menten constant; $\mathrm{V}_{\max }$, maximum velocity; OAA, oxaloacetate.

difference was identified between the increase of $\mathrm{MDH}$ activity following 10 and $20 \mathrm{mM}$ oxamate treatment $(\mathrm{P}>0.05)$.

\section{Discussion}

High aerobic glycolysis is one of the main hallmarks of cancer cells, which is driven by multiple enzymes. The enzyme rate is regulated via two different processes as follows: i) Change in the total quantity of the enzyme present $\left(\mathrm{V}_{\max }\right)$; ii) change in one or more kinetic constants $\left(\mathrm{K}_{\mathrm{m}}\right.$ or $\left.\mathrm{V}_{\max }\right)$. These processes and the enzyme stability are strongly influenced by the composition of the intracellular milieu in which the enzyme operates (10). Given the different microenvironmental conditions of the tumor compared with the healthy tissue, the enzyme function may differ between healthy tissue and tumor samples. The data from the current study supported the hypothesis and indicated that the kinetics of $\mathrm{MDH}$, as one of the important enzymes in metabolism, has a distinctive feature in tumors and may be an alternative approach for supporting the glycolysis pathway.

The maximum activity measured was assumed to be primarily due to the cytosolic fraction, as the highest concentration of OAA used in the assay method (1 mM) was considerably greater than that (by $0.04 \mathrm{mM}$ ), which was known to inhibit the activity of the mitochondrial fraction (14). Furthermore, to demonstrate that the samples were free of the mitochondrial enzyme form, the supernatants, made from specimens, were assessed for NADH oxidase activity, as the mitochondrial marker and the interrupter of dehydrogenase. The results clarified that there was no NADH oxidase activity; therefore, the supernatant was free of mitochondrial particles.

The present data indicated that the maximum activity of the cancerous $\mathrm{MDH}(\mathrm{C}-\mathrm{MDH})$ for producing $\mathrm{NAD}^{+}$and malate is higher than the normal MDH (N-MDH). This result is consistent with the current hypothesis regarding the role of $\mathrm{MDH}$ in supporting $\mathrm{NAD}^{+}$pool. In addition, a greater $\mathrm{V}_{\max }$ of $\mathrm{MDH}$ causes a higher level of $\mathrm{NAD}^{+}$, which may be used as a precursor for sustaining a high rate of aerobic glycolysis in tumors. According to the attained results, the required $\mathrm{NAD}^{+}$ for the continuous flow of glycolysis may be supplied by cytoplasmic MDH in addition to eminent LDH in tumors. In the current study, the LDH kinetics in tumor and healthy tissue samples were evaluated. The $\mathrm{V}_{\max }$ of $\mathrm{C}$-LDH for the generation 
A

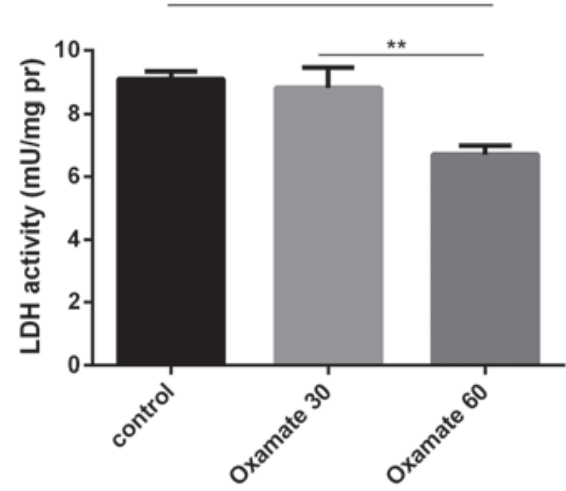

B

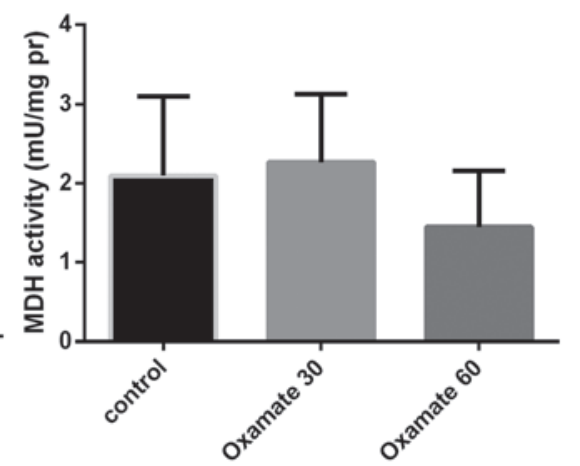

C

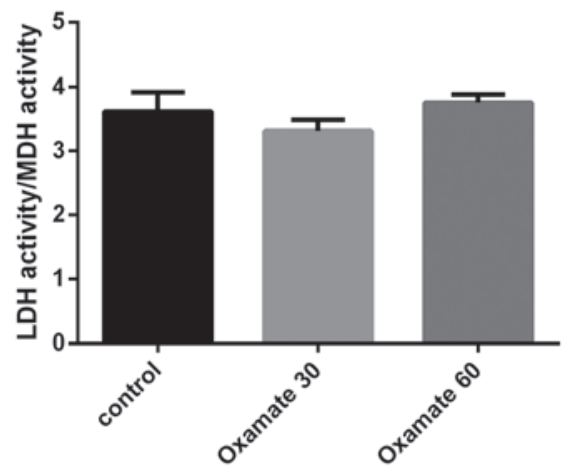

Figure 1. LDH and MDH activity patterns in the MCF-7 cell line with and without (control) LDH inhibitor, oxamate (30 and $60 \mathrm{mM}$ ). (A) LDH activity was significantly decreased by $60 \mathrm{mM}$ oxamate, although not with $30 \mathrm{mM}$ oxamate. (B) $\mathrm{MDH}$ activity was not affected as a result of LDH inhibition. (C) LDH/MDH activity ratio was unchanged following $\mathrm{LDH}$ inhibition. $\mathrm{LDH}$, lactate dehydrogenase; $\mathrm{MDH}$, malate dehydrogenase; pr, protein. ${ }^{* *} \mathrm{P}<0.01$.

A

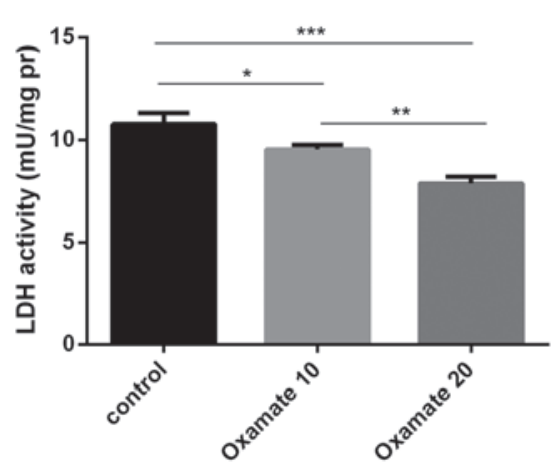

B

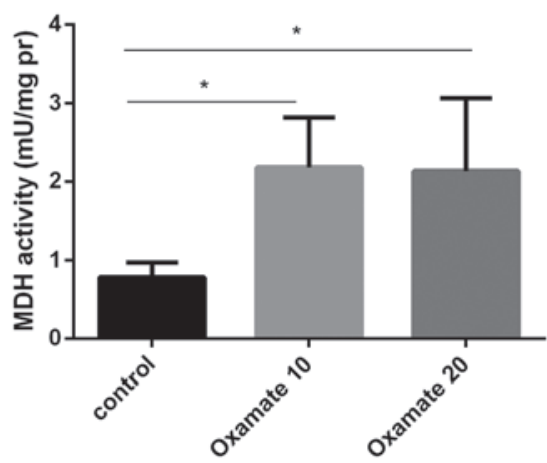

C

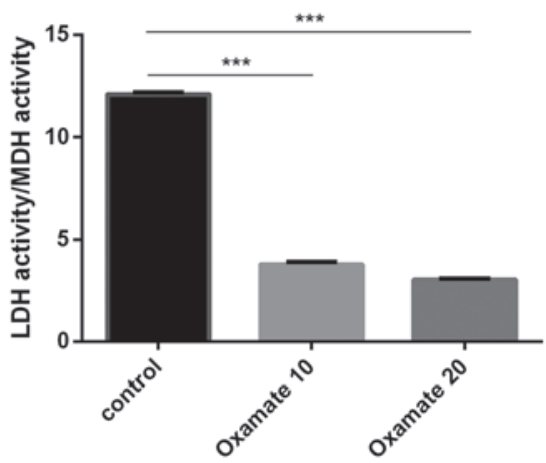

Figure 2. LDH and MDH activity patterns in the MDA-MB231 cell line with and without (control) LDH inhibitor, oxamate (10 and 20 mM). (A) Compared with the control, LDH activity was significantly decreased with 10 and $20 \mathrm{mM}$ oxamate. The difference between 10 and $20 \mathrm{mM}$ oxamate was also significant. (B) MDH activity significantly increased following LDH inhibition with 10 and $20 \mathrm{mM}$ oxamate compared with the control. (C) LDH/MDH activity ratio was decreased compared with the control, following LDH inhibition with 10 and $20 \mathrm{mM}$ oxamate. ${ }^{*} \mathrm{P}<0.05 ;{ }^{* *} \mathrm{P}<0.01 ;{ }^{* * * *} \mathrm{P}<0.001$.

of $\mathrm{NAD}^{+}$and pyruvate was $\sim 2$-fold higher than N-LDH. This is consistent with previous studies, which demonstrated markedly higher LDH activity and gene expression in tumors when compared to the relevant healthy samples $(5,18,19)$. In the current study, while LDH and MDH had the same maximum activity in the healthy samples, in the tumor samples, the two were increased and LDH had a greater $\mathrm{V}_{\max }$ than $\mathrm{MDH}$, demonstrating the more significant role of $\mathrm{LDH}$ in tumorigenesis. Thus, increasing the activity of LDH and MDH may be a strategy of tumorigenesis and proliferation for adapting to the stressful tumor environment.

Malic enzyme (ME) produces more pyruvate from the abundant quantity of malate generated by C-MDH. Pyruvate is used as an LDH substrate and supports high aerobic glycolysis (20). Therefore, MDH, through producing a high level of malate, sustains a high glycolysis rate in an indirect model. Thus, $\mathrm{MDH}$ supports high aerobic glycolysis in tumors by generating two metabolites: $\mathrm{NAD}^{+}$and malate. In order to verify the role of $\mathrm{MDH}$ in supporting glycolysis, the MDH activity was measured in breast cancer cell lines, treated by oxamate (the inhibitor of LDH). Notably, the reduction of LDH activity by oxamate was concomitant with the increase of the MDH activity in MDA-MB-231 cells, although the MDH activity in the MCF-7 cells was stable following oxamate treatment. Furthermore, the ratio of $\mathrm{LDH}$ to $\mathrm{MDH}$ demonstrated the pattern of the $\mathrm{MDH}$ activity increment subsequent to oxamate treatment. The ratio of LDH to MDH decreased in the MDA-MB-231 cells following oxamate treatment; however, no change was observed in the MCF-7 cells (Figs. 1 and 2). Increasing the MDH activity in MDA-MB-231 cells, compared with the MCF-7 cells, is associated with the glycolysis patterns in the two cancer cell types. MDA-MB-231 cells have a higher rate of glycolysis than MCF-7 cells and are more dependent on glycolysis as the main energy source (21). Thus, MDA-MB-231 cells were more susceptible to glycolysis and LDH inhibition. It is conceivable that cancer cells increase the MDH activity to compensate for the LDH deficiency and produce $\mathrm{NAD}^{+}$for sustaining a high rate of aerobic glycolysis, even though the production rate of $\mathrm{NAD}^{+}$by $\mathrm{MDH}$ in comparison with $\mathrm{LDH}$ is negligible. This finding can also be considered in LDH-associated cancer therapy, where LDH is targeted to disrupt the glycolysis pathway as the mainstream energy pathway in cancer cells. In recent years, efforts have been made to eliminate LDH activity and gene expression $(22,23)$. Evaluation of alternative metabolism pathways is required, where LDH activity is inhibited to halt the glycolysis pathway, as the cancer cells employ various approaches (such as MDH) to 
repair their deficiency in order to support the glycolysis pathway. Given the role of MDH in supporting glycolysis, inhibition of $\mathrm{MDH}$ activity and gene expression, concomitant with $\mathrm{LDH}$, may assist with halting the glycolysis pathway and enhancing LDH removal efficiency. Furthermore, the obtained results regarding increasing $\mathrm{MDH}$ activity in the presence of oxamate are consistent with a previous report (21), which indicated the more malignant MDA-MB-231 cells are more dependent on glycolysis and LDH than the benign MCF-7 cells.

The current data are not consistent with the findings of Balinsky et al (24) where they demonstrated that cytosolic MDH in tumor and healthy breast tissues exerts the same activity, whereas the current results demonstrate that $\mathrm{MDH}$ has higher maximal activity in tumor tissue samples when compared with healthy tissue samples. The difference between these two studies may be associated with the various methods applied, for example Balinsky et al (24) used an electrophoretic method for enzyme activity detection whereas a spectrophotometric assay of LDH and MDH activities was used in the current study. The results regarding the $\mathrm{K}_{\mathrm{m}}$ of the forward reaction are in contrast to the results of the study by Grisham et al (13), which is one of the initial studies on the kinetics of MDH in tumors. The current results indicated that the affinity of $\mathrm{MDH}$ in forward reaction is the same in tumor and healthy tissue samples. By contrast, Grisham et al (13) expressed that the $\mathrm{K}_{\mathrm{m}}$ of OAA in tumor samples was higher than that in healthy tissue samples. Therefore, it can be concluded that the difference between these two studies is justified by considering the fact that Grisham et al (13) used 0.2 and $2 \mathrm{mM}$ of OAA as the highest concentration of OAA in healthy and tumor tissue samples, respectively, whereas in the current study, the highest OAA concentration in the two tissue types was $1 \mathrm{mM}$. The present data demonstrated that the concentrations $>1 \mathrm{mM}$ exerted an inhibitory effect on $\mathrm{MDH}$ activity and that $1 \mathrm{mM}$ was the optimum concentration in the two types of tissue.

The kinetic differences indicated that MDH from healthy and tumor tissue samples may exist in distinct structural states, which may be associated with the various tumor microenvironmental conditions. The condition of the milieu, where the enzyme operates, may affect the enzyme kinetics. It is important to note that the kinetic diversity of MDH may be due to post-translational modification during tumorigenesis. Further investigations are required to detect the post-translational modification of MDH in cancer tissue samples and recognize the effect on the MDH structure and the kinetic parameters.

In conclusion, the hypothesis of the present study, which addressed the kinetics and role of $\mathrm{MDH}$ in supplying $\mathrm{NAD}^{+}$, remains unanswered as the enzyme were not purified and fully characterized. However, the results obtained in the current study are, to the best of our knowledge, the first step in this field. The results highlight another approach to support glycolysis in MDA-MB-231 and propose that cancer cells adapt to a situation, where the energy generation pathway is targeted through LDH inhibition.

\section{Acknowledgements}

The present study was funded by grants from Shahid Beheshti University of Medical Sciences (Tehran, Iran; grant no. 93/10/09/13061) and Shahid Chamran University of Ahvaz Research Council (Ahvaz, Iran; grant no. 94/3/02/31580).

\section{References}

1. Hanahan D and Weinberg RA: Hallmarks of cancer: The next generation. Cell 144: 646-674, 2011.

2. Warburg O: On the origin of cancer cells. Science 123: 309-314, 1956.

3. Gatenby RA and Gillies RJ: Why do cancers have high aerobic glycolysis? Nat Rev Cancer 4: 891-899, 2004.

4. Talaiezadeh A, Shahriari A, Tabandeh MR, Fathizadeh P and Mansouri S: Kinetic characterization of lactate dehydrogenase in normal and malignant human breast tissues. Cancer Cell Int 15: 19, 2015.

5. Koukourakis MI, Giatromanolaki A, Simopoulos C, Polychronidis A and Sivridis E: Lactate dehydrogenase 5 (LDH5) relates to up-regulated hypoxia inducible factor pathway and metastasis in colorectal cancer. Clin Exp Metastasis 22: 25-30, 2005.

6. Rong Y, Wu W, Ni X, Kuang T, Jin D, Wang D and Lou W: Lactate dehydrogenase $\mathrm{A}$ is overexpressed in pancreatic cancer and promotes the growth of pancreatic cancer cells. Tumour Biol 34: 1523-1530, 2013.

7. Israël $\mathrm{M}$ and Schwartz L: The metabolic advantage of tumor cells. Mol Cancer 10: 70, 2011.

8. DeBerardinis RJ, Lum JJ, Hatzivassiliou G and Thompson CB: The biology of cancer: Metabolic reprogramming fuels cell growth and proliferation. Cell Metab 7: 11-20, 2008

9. Murray RK, Granner DK, Mayes PA and Rodwell VW: Harper's illustrated biochemistry. 26th edition. McGraw-Hill, New York, NY, 2003

10. Storey KB and Brooks SPJ: The basis of enzymatic adaptation. Principles of Medical Biology 4 (Part 1): 147-169, 1995.

11. Fukumura D and Jain RK: Tumor microenvironment abnormalities: Causes, consequences, and strategies to normalize. J Cell Biochem 101: 937-949, 2007.

12. Cairns RA, Harris IS and Mak TW: Regulation of cancer cell metabolism. Nat Rev Cancer 11: 85-95, 2011.

13. Grisham MB, Bernstein LH and Everse J: The cytoplasmic malate dehydrogenase in neoplastic tissues; presence of a novel isoenzyme? Br J Cancer 47: 727-731, 1983.

14. Belfiore F, Borzi V, Vecchio LL, Napoli E and Rabuazzo AM: Enzyme activities of NADPH-forming metabolic pathways in normal and leukemic leukocytes. Clin Chem 21: 880-883, 1975.

15. Bradford MM: A rapid and sensitive method for the quantitation of microgram quantities of protein utilizing the principle of protein-dye binding. Anal Biochem 72: 248-254, 1976.

16. Brooks SPJA: A simple computer program with statistical tests for the analysis of enzyme kinetics. Biotechniques 13: 906-911, 1992.

17. Brooks SPJA: A program for analyzing enzyme rate data obtained from a microplate reader. Biotechniques 17: 1154-1161, 1994.

18. Koukourakis MI, Kontomanolis E, Giatromanolaki A, Sivridis E and Liberis V: Serum and tissue LDH levels in patients with breast/gynaecological cancer and benign diseases. Gynecol Obstet Invest 67: 162-168, 2009.

19. Koukourakis MI, Giatromanolaki A, Winter S, Leek R, Sivridis E and Harris AL: Lactate dehydrogenase 5 expression in squamous cell head and neck cancer relates to prognosis following radical or postoperative radiotherapy. Oncology 77: 285-292, 2009.

20. Deberardinis RJ, Sayed N, Ditsworth D and Thompson CB: Brick by brick: Metabolism and tumor cell growth. Curr Opin Genet Dev 18: 54-61, 2008

21. Robey IF, Lien AD, Welsh SJ, Baggett BK and Gillies RJ: Hypoxia-inducible factor- $1 \alpha$ and the glycolytic phenotype in tumors. Neoplasia 7: 324-330, 2005.

22. Allison SJ, Knight JR, Granchi C, Rani R, Minutolo F, Milner J and Phillips RM: Identification of LDH-A as a therapeutic target for cancer cell killing via (i) p53/NAD(H)-dependent and (ii) p53-independent pathways. Oncogenesis 3: e102,2014.

23. Shi $\mathrm{Y}$ and Pinto BM: Human lactate dehydrogenase a inhibitors: A molecular dynamics investigation. PLoS One 9: e86365, 2014.

24. Balinsky D, Platz CE and Lewis JW: Isozyme patterns of normal, benign, and malignant human breast tissues. Cancer Res 43: 5895-5901, 1983 